University of Nebraska - Lincoln

DigitalCommons@University of Nebraska - Lincoln

Faculty Publications, Department of Psychology

Psychology, Department of

December 2006

\title{
Linking Self-Regulation and Risk Proneness to Risky Sexual Behavior: Pathways through Peer Pressure and Early Substance Use
}

\author{
Lisa J. Crockett \\ University of Nebraska-Lincoln, ecrockett1@unl.edu \\ Marcela Raffaelli \\ University of Nebraska-Lincoln, mraffaelli1@unl.edu \\ Yuh-Ling Shen \\ University of Nebraska-Lincoln
}

Follow this and additional works at: https://digitalcommons.unl.edu/psychfacpub

Part of the Psychiatry and Psychology Commons

Crockett, Lisa J.; Raffaelli, Marcela; and Shen, Yuh-Ling, "Linking Self-Regulation and Risk Proneness to Risky Sexual Behavior: Pathways through Peer Pressure and Early Substance Use" (2006). Faculty Publications, Department of Psychology. 132.

https://digitalcommons.unl.edu/psychfacpub/132

This Article is brought to you for free and open access by the Psychology, Department of at DigitalCommons@University of Nebraska - Lincoln. It has been accepted for inclusion in Faculty Publications, Department of Psychology by an authorized administrator of DigitalCommons@University of Nebraska - Lincoln. 


\title{
Linking Self-Regulation and Risk Proneness to Risky Sexual Behavior: Pathways through Peer Pressure and Early Substance Use
}

\author{
Lisa J. Crockett, Marcela Raffaelli, and Yuh-Ling Shen \\ University of Nebraska-Lincoln
}

\begin{abstract}
The linkages between self-regulation in childhood, risk proneness in early adolescence, and risky sexual behavior in midadolescence were examined in a cohort of children $(N=518)$ from the National Longitudinal Survey of Youth. The possible mediating role of two early adolescent variables (substance use and negative peer pressure) was also examined. Self-regulation was assessed by maternal report at ages 8-9, and risk proneness, comprising aspects of sensation seeking and decision making, was assessed by adolescent self-report at ages 12-13. Structural equation models predicting risky sexual behavior at ages 16-17 indicated that self-regulation operated partly through early adolescent substance use, whereas risk proneness operated through early adolescent substance use and negative peer pressure. The overall model did not differ significantly for boys and girls, although there were gender differences in the strength of particular paths. These longterm longitudinal results support the importance of early self-regulation and risk proneness in setting the stage for adolescent sexual risk taking and implicate substance use and negative peer pressure as processes through which risk proneness and poor self-regulation lead to risky sexual behavior.
\end{abstract}

In recent years, self-regulation, defined as the ability to regulate one's attention, affect, and activity in accordance with internal and external demands, has emerged as an important determinant of children's psychosocial adjust- 
ment. Theoretical models (e.g., Block \& Block, 1980; Demetriou, 2000; Kopp 1982) suggest that self-regulation facilitates adaptive responses to life's challenges, and several reviews of the literature support a link between self-regulatory capacity and children's competence (Barkley, 1997; Baumeister, Leith, Muraven, \& Bratslavsky, 1998; Eisenberg \& Fabes, 1999; Shonkoff \& Phillips, 2000). To date, empirical work has tended to focus on childhood, with less attention devoted to the developmental consequences of self-regulatory capacity in adolescence. However, several studies have supported an association between self-regulation (or related constructs) and adolescent adjustment. For example, children low in ego control report elevated substance use and externalizing behavior as adolescents (Block, Block, \& Keyes, 1988; Caspi, Henry, McGee, Moffitt, \& Silva, 1995). Building on this work, the present study investigated the link between childhood self-regulation and risky sexual behavior in adolescence.

Risky sexual behavior such as early intercourse, unprotected intercourse, or sex with multiple partners contributes to high rates of pregnancy and sexually transmitted infections among adolescents in the United States (Grunbaum et al., 2004; Moore, Manlove, Terry-Humen, Williams, Papillo, \& Scarpa, 2001). Prior work has documented a prospective association between poor self-regulation (or low self-restraint) in early adolescence and subsequent risky sexual behavior (Feldman \& Brown, 1993; Raffaelli \& Crockett, 2003). Here, we extend the temporal canvas to examine the relation between children's self-regulatory skills and their risky sexual behavior in mid-adolescence 8 years later. Additionally, we investigated the pathways linking selfregulation and sexual risk taking, focusing on two potential mediators: early adolescent substance use and negative peer pressure. In a parallel fashion, we also examined a second individual characteristic - risk proneness - and the pathways through which it influences sexual risk taking.

\section{SELF-REGULATION AND SEXUAL RISK TAKING}

Self-regulation denotes a capacity to regulate attention, affect, and behavior in ways that are attuned to internal and contextual demands (Kopp, 1982; Zimmerman, 2000). The capacity for self-regulation is believed to develop in childhood, beginning with parent-mediated behavioral and emotional regulation in infancy and becoming increasingly internalized in the preschool years with the development of symbolic representation and the emergence of executive functions (Bronson, 2000; Kopp, 1982; Shonkoff \& Phillips, 2000). Aspects that require more abstract thinking, such as the capacity to envision long-term goals and to regulate one's behavior in line with those goals, like- ly do not develop until late childhood or adolescence (Demetriou, 2000). Although conceptually distinct, the affective, cognitive, and behavioral components of self-regulation appear to form a single latent factor that can be identified as early as the preschool years (Raffaelli, Crockett, \& Shen, 2005; Tarter et al., 2003). There is also evidence that individual differences in self-regulation emerge early in childhood and are fairly stable. Murphy, Eisenberg, Fabes, Shepard, and Guthrie (1999) reported $r$ 's ranging from .41 to .67 in parent-reported dimensions of child self-regulation from ages 6-8 to ages 1012. More recently, Raffaelli et al. (2005) found moderate stability in motherreported self-regulation during childhood and early adolescence ( $r$ 's ranged from .47 to .50 over 4-year intervals).

Feldman and Weinberger (1994) proposed that youth who develop strong self-regulatory skills in middle childhood are better equipped to avoid risky behavior in adolescence including risky sexual behavior. In line with this notion, Feldman and Brown (1993) found that boys' self-restraint at ages 10-11 was inversely associated with the number of sexual partners 4 years later. Furthermore, in a cross-sectional study of adolescent girls seeking clinic services for either contraceptive advice or termination of a pregnancy, impulsiveness significantly predicted membership in the pregnancy group (Rawlings, Boldero, \& Wiseman, 1995). More recently, Raffaelli and Crockett (2003) demonstrated an association between self-regulatory capacity in early adolescence and risky sexual behavior in mid-adolescence in a national sample of boys and girls. Together, these findings suggest that adolescents' self-regulatory capacities can influence their sexual risk taking. However, less is known about the impact of childhood self-regulation on risky sexual behavior in adolescence. The first goal of the present study was to examine this association.

\section{RISK PRONENESS}

Risk proneness or risk tolerance is characterized by attraction to excitement and ineffective decision making. Individuals who are attracted to excitement may seek out dangerous or risky situations. Risk-prone youth may also engage in risky behavior because they focus on positive emotional outcomes (e.g., fun, excitement) and discount the possible negative consequences (see Beyth-Marom \& Fischoff, 1997, for a review of adolescent decision making). Thus, risk proneness is distinguished from poor self-regulation by its motivational component: whereas adolescents with poor self-regulatory skills are unable to regulate their affect, attention, or behavior sufficiently to avoid trouble, risk-prone adolescents may choose not to use their self-regulatory abilities when opportunities for excitement arise. A related character- 
istic, sensation seeking, has been linked to risky sexual behavior in prior research (Farley, 1991; Zuckerman, 1991) including earlier sexual debut and a greater number of partners. Recently, we demonstrated a predictive association between risk proneness and risky sexual behavior (Raffaelli \& Crockett, 2003). Risk proneness, assessed in early adolescence, showed a significant bivariate association with sexual risk taking 4 years later; however, the association was no longer significant when peer pressure and independent decision making were included in multivariate models. The present study extends that work by exploring the pathways through which risk proneness may contribute to risky sexual behavior.

\section{MEDIATING PROCESSES}

A second major goal of the present study was to identify intervening processes through which self-regulation and risk proneness influence sexual behavior. High risk proneness and poor self-regulation may operate directly on sexual risk taking, for example, by increasing an adolescent's motivation to engage in risky behavior or by increasing impulsiveness. However, self-regulation and risk proneness may also operate indirectly, by promoting experiences in early adolescence that increase the likelihood of risky sexual behavior later on. Two likely intervening variables are early substance use and exposure to negative peer pressure. The hypothesized indirect paths are depicted in Figure 1.

\section{Substance use}

Poor self-regulation and risk proneness may each predispose adolescents to early substance use. Cooper (1994) has proposed that negative affect is a motivating factor in substance use, prompting the use of substances as a coping mechanism. Poor self-regulators may be especially vulnerable to this form of coping, because they are unskilled at regulating their emotions and tend to rely on external structures to regulate their emotional functioning (Diaz \& Fruhauf, 1991). In line with these expectations, adolescents who are low in ego or impulse control also report higher levels of drug use (Block et al., 1988; Colder \& Chassin, 1997). Farrell and Danish (1993) found that for seventh-grade boys but not girls, low emotional restraint was significantly associated with increases in gateway drug use over the next 6 months. Behavioral and cognitive self-regulation are also implicated in substance use. For example, low self-control at ages 11-12 predicted heavier alcohol use 1 year later (Brody \& Ge, 2002). In a sample of 10-12-year-old boys, cognitive exec-

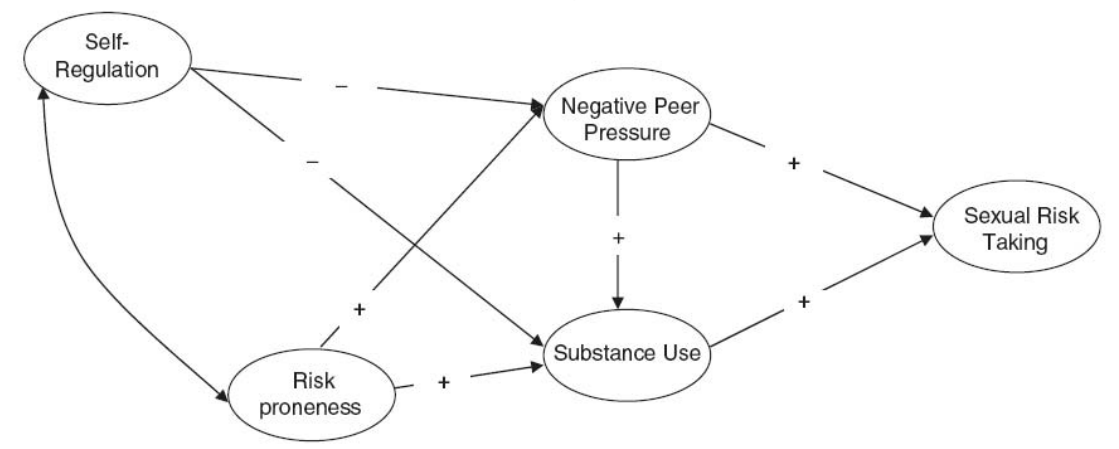

FIGURE 1 Conceptual model linking childhood self-regulation to risky sexual behavior (straight lines indicate causal paths; curved lines indicate correlations).

utive function predicted substance use 2 years later (Aytaclar, Tarter, Kirisci, $\& \mathrm{Lu}, 1999$ ), and neurobehavioral disinhibition (a latent variable reflecting affect, cognition, and behavior) predicted early onset of substance use disorder 7-9 years later (Tarter et al., 2003).

Risk-prone adolescents may use substances because the experience is novel and exciting and because they focus on these aspects and ignore the possible negative consequences. A related construct, sensation seeking, is associated with adolescent substance use (Tarter, 2002; Zucker, Fitzgerald, \& Moses, 1995). In turn, substance use can increase the risk of unprotected intercourse by reducing social inhibition, impairing decision making and negotiation skills, and reducing inhibitory control. Alcohol use, in particular, is associated with cognitive impairments (Koelega, 1995; Peterson, Rothfleisch, Zelazo, \& Pihl, 1990), which may increase the risk of unprotected sex. Recent survey data showed that $25 \%$ of sexually active high school students in the United States used alcohol or drugs at their most recent sexual intercourse (Grunbaum et al., 2004). Among girls, overall levels of alcohol use have been linked to unwanted intercourse (Buzy et al., 2004; Pederson \& Skrondal, 1996).

\section{Peer pressure}

A second pathway to risky sexual behavior involves association with peers 
who encourage risk taking. Among adolescents, affiliation with deviant and sexually active peers is linked to greater likelihood of sexual behavior (Rodgers \& Rowe, 1990; Whitbeck, Conger, \& Kao, 1993), and peer pressure to engage in misconduct is positively associated with substance use and delinquent behavior (Brown, Clasen, \& Eicher, 1986). Poor self-regulation and high risk proneness could each increase affiliation with deviant peers. For example, inability to regulate one's affect and behavior may lead to association with peers who are similarly undercontrolled and impulsive. Farrell and Danish (1993) found that restraint in seventh grade predicted both peer models of drug use and peer pressure for drug use as well as gateway drug use 6 months later. Similarly, risk-prone adolescents may seek out peers who share their attraction to the excitement of risky behavior. In summary, poor self-regulation and higher risk proneness may lead to association with deviant peers and negative peer pressure that, in turn, increase the likelihood of substance use and risky sexual behavior.

\section{GENDER DIFFERENCES IN PATHWAYS}

Boys tend to report earlier first intercourse and more sexual partners than girls do, suggesting that they engage in more sexual risk taking (Grunbaum et al., 2004). Moreover, it is possible that the mediating processes are different for girls and boys. According to sexual script theory (Gagnon, 1973), girls are expected to be the gatekeepers for sex; if so, their substance use might have a larger impact on whether unprotected sex occurs. Additionally, some research suggests that girls are more influenced by their best friends' sexual behavior than boys are (Smith, Udry, \& Morris, 1985). If so, the pathway from negative peer pressure to sexual risk taking might be stronger for girls. Finally, evidence for effects of self-regulation on substance use is stronger for boys than for girls (Farrell \& Danish, 1993). To explore these possibilities, we examined gender differences in pathways to sexual risk taking.

\section{THE PRESENT STUDY}

Although prior studies support the role of self-regulation in risky sexual behavior, it is important to establish how early this link emerges. Lack of selfregulatory ability in childhood may set the stage for early forms of risk taking (e.g., substance use) that in turn increase the likelihood of sexual risk taking. If so, it might be possible to prevent multiple kinds of risk taking by enhancing self-regulatory capacity. Moreover, early assessment of self-regulation would increase the lead-time for preventive interventions. Building on prior work that has examined self-regulation in preadolescence or early adolescence (Feldman \& Brown, 1993; Raffaelli \& Crockett, 2003), we examined the association between self-regulatory capacity in middle childhood and sexual risk taking in mid-adolescence. A second goal was to identify the pathways through which early self-regulation and risk proneness in early adolescence influence sexual risk taking. Although a number of studies have examined specific paths in our conceptual model (Figure 1), especially those linking self-regulation and substance use, to our knowledge, no studies have applied this integrative model to sexual risk taking. In examining the model, we addressed three research questions. First, is self-regulatory capacity in middle childhood predictive of risky sexual behavior in mid-adolescence? Based on previous studies of self-regulation in pre-or early adolescence, we expected this association to be supported. Second, do the effects of self-regulation and risk proneness on sexual risk taking operate through negative peer pressure and substance use in early adolescence? We expected these indirect pathways to be supported. Third, are there gender differences in these pathways? Because the prior literature on gender differences in these pathways is sparse, we did not make specific predictions.

Sexual risk taking is associated with age and race/ethnicity. Compared with younger adolescents, older youth are more likely to report having sex and engaging in risky sexual behaviors (Grunbaum et al., 2004). AfricanAmerican adolescents are more likely to have sex but also more likely to report using condoms than white and Hispanic youth (Grunbaum et al., 2004). Additionally, family structure, mother's educational level, and mother's timing of childbearing have been linked to age of sexual debut among adolescents (see Miller, Benson, \& Galbraith, 2001 for a review). These family variables, along with child age and race/ethnicity, were included as control variables in the primary analyses.

\section{METHOD}

\section{Sample}

Data came from the mother-child data set of the National Longitudinal Survey of Youth (NLSY). The NLSY began in 1979 with a national probability sample of 12,686 youth who were between the ages of 14 and 21 in January 1979 (Zagorsky \& White, 1999). Blacks, Hispanics, and economically disadvantaged non-Hispanic whites were oversampled initially (the economically disadvantaged white oversample was later dropped). Participants have been surveyed on an annual basis since 1979. Beginning in 1986, the chil- 
dren of female participants were added to the study and have been assessed at 2 -year intervals. The sample for the present study was based on a cohort of 750 children (47\% female) aged 8-9 in 1990 (T1), 690 (92\%) of whom were present in 1994 (T2) and 653 (87\%) in 1998 (T3). In cases where multiple siblings participated in the study, one sibling from each family was randomly selected for inclusion in the cohort. The final analytic sample size was 518 owing to attrition $(n=97)$ and to missing data $(n=135)$ on variables of interest. Sample sizes for tests of measurement models are larger than those for structural equation models because they involve fewer variables and hence less missing data.

To examine possible sample bias, the final sample $(N=518)$ was compared with those lost for any reason $(n=232)$ on Time 1 demographic characteristics and self-regulation and on Time 2 risk proneness, substance use, and negative peer pressure scores. The only significant difference was in gender composition, reflecting greater attrition of boys. The final sample was evenly divided by gender (255 boys and 263 girls) and included 117 Hispanic (23\%), 186 black (36\%), and 215 white (41\%) children. Mother's average age at the birth of their first child was 19 years $(S D=2.36)$.

\section{Measures}

Primary measures were drawn from three waves of data: 1990, 1994, and 1998 (see Appendix for measures and assessment times). Self-regulation was assessed in 1990, when children were 8-9 years old (T1). Risk proneness and the two hypothesized mediators (negative peer pressure and substance use) were assessed in 1994, when children were ages 12-13 years (T2). (Risk proneness was not measured in 1990.) Sexual risk taking was measured in 1998 at ages 16-17 (T3). Demographic controls were assessed in 1986 or in 1998 , depending on the variable. For multi-item scales, valid data on at least $50 \%$ of the items were required for creating scale scores.

Self-regulation. The self-regulation measure consisted of 13 conceptually identified items from the 28-item Behavior Problems Index (Peterson \& Zill, 1986; Zill, 1990). Consistent with our conceptualization of self-regulation as a multidimensional construct, we included items reflecting regulation of affect, attention, and behavior. Affect items tapped into both emotional volatility (e.g., "he/she has sudden changes in mood or feeling") and intensity of expressed emotion (e.g., "he/she has a very strong temper and loses it easily"). "He/she has difficulty concentrating, cannot pay attention for long" was an indicator of attention regulation, and "he/she is restless or overly active, cannot sit still" was an indicator of behavior regulation. Mothers reported how well each item described their child's behavior in the last 3 months, using a three-point scale from 1 (often true) to 3 (not true). The 13 items were reverse scored and averaged so that a higher score indicated better self-regulation $(\alpha=.85)$. To ensure that the measure of self-regulation did not overlap with pre-existing externalizing problems, we excluded items indicative of antisocial behavior, peer problems, and oppositional behavior. Items similar to those included in the self-regulation measure have been used in research that examines emotionality and self-regulation (e.g., Eisenberg et al., 1995; Lengua, 2002), self-restraint (Feldman \& Brown, 1993), and impulsiveness (Eysenck \& Eysenck, 1978). Developmental scholars agree that parents can provide valid and reliable ratings of their children's personality (Rothbart \& Bates, 1998). Indeed, parent and teacher ratings tend to be consistent with each other (e.g., Guerin \& Gottfried, 1994; Murphy et al., 1999), bolstering confidence in parent ratings as a source of data.

Risk proneness. Adolescents responded to six self-report items assessing their motivation for excitement (e.g., "I enjoy taking risks"; Little Known Variables in the NLS, 2000) and their preference for spontaneous decision making as opposed to forethought (e.g., "I think that planning takes fun out of things"). Responses were made on a four-point scale ranging from 1 (strongly disagree) to 4 (strongly agree). Items were averaged to create a composite measure $(\alpha=.67)$, with higher scores indicating greater risk proneness.

Negative peer pressure. Self-reported peer pressure to engage in misconduct or delinquent activities was assessed with five yes-no items (e.g., "Do you ever feel pressure from your friends to skip school?"). Initially, a scale score was computed by averaging across the responses $(\alpha=.72)$. Because the distribution was highly skewed (few adolescents reported peer pressure on any given item), a dichotomous variable was created that indicated whether children reported experiencing any negative peer pressure $(0=$ no, $1=$ yes $)$.

Early substance use. The substance use measure consisted of five self-report items covering lifetime use of alcohol, tobacco, marijuana, other drugs, and inhalants (e.g., "Have you ever smoked a cigarette?"). Responses were coded as 0 (no) or 1 (yes). A total substance use score was computed by summing across the five items and dividing by the number of valid items. Possible scores ranged from 0 to 1 , with a higher score indicating more substances tried. A square root transformation was applied to reduce skewness and kurtosis. 
Risky sexual behavior. At ages 16-17, adolescents completed self-administered measures of sexual experience. Youth were asked whether they had ever had intercourse; those who responded "yes" were asked to report their age at first intercourse, number of sex partners in the last 12 months, and condom use at last intercourse. Risky sexual behavior is a multidimensional construct reflecting a number of different behaviors including sexual intercourse, early intercourse, sex without a condom, and multiple partners (Grunbaum et al., 2004). Therefore, we created a measure of cumulative sexual risk by scoring the different sexual behavior variables dichotomously and summing. Scores ranged from 0 (no risk; i.e., never had sex) to 4 (high risk; i.e., sexually active, sexual debut before age 15, two or more sex partners in the last 12 months, no condom use at last intercourse). This composite variable indexes the overall risk associated with an adolescent's sexual history.

Demographic variables. Adolescents reported their age (in years) in 1998. Mothers reported their children's race and gender in 1986. Race was captured as two dummy variables corresponding to black $(1=$ black; $0=$ oth er $)$ and Hispanic $(1=$ Hispanic; $0=$ other $)$, respectively. Gender was coded as 1 (boys) or 0 (girls). Additionally, in 1986, mothers reported how old they were when their first child was born, whether they had finished high school, and current family structure $(1=$ two biological parents in the home; $0=$ oth$e r)$. These demographic variables were all examined in preliminary analyses; however, the last two did not contribute to the predictive model and were dropped from the main analyses.

\section{Analysis Plan}

Analysis proceeded in three phases. Initially, bivariate associations between the predictors and sexual risk taking were examined. Next, the proposed structural model in Figure 1 was tested for the total sample of boys and girls using structural equation modeling (SEM) with LISREL 8.5 (Jöreskog \& Sörbom, 2002). Although the effects of self-regulation and risk proneness were expected to operate through substance use and negative peer pressure, we tested the model with and without direct paths from self-regulation and risk proneness to sexual risk taking in order to identify significant direct effects. Finally, to examine gender differences in predictive models, a two-group SEM in which estimates for each gender were free to vary was compared with one in which the paths for boys and girls were constrained to be equal; significant differences in models were assessed using a $\chi^{2}$ difference test.
Models were evaluated with multiple fit indices. In addition to the $\chi^{2}$ test, which is sensitive to sample size (Kline, 1998), the goodness of fit index (GFI), the comparative fit index (CFI), and the root mean squared error of approximation (RMSEA) were examined. An adequate fit was indicated by a GFI and a CFI greater than .90 and an RMSEA less than .10 (Jöreskog \& Sörbom, 1993; Kelloway, 1998; Kline, 1998).

\section{RESULTS}

\section{Preliminary Analyses}

Bivariate correlations among study variables are shown in Table 1. As expected, self-regulation and risk proneness scores (based on scale means) were significantly correlated with sexual risk scores: adolescents with lower selfregulation or higher risk proneness reported more sexual risk taking. Additionally, negative peer pressure and substance use were significantly and positively associated with risky sexual behavior. Among the demographic variables, child age, and mother's age at the birth of her first child were significantly correlated with sexual risk taking: older adolescents and the children of early child bearers reported more risky sexual behavior. Moreover, negative peer pressure and substance use were significantly intercorrelated.

\section{Variable Treatment for the Structural Models}

In the primary analyses, self-regulation and risk proneness were modeled as latent variables measured with multiple indicators: self-regulation was measured with 13 observed indicators and risk proneness with six observed indicators. The mediating variables (substance use and peer pressure) and the outcome variable (risky sexual behavior) were modeled as latent variables with single observed indicators (i.e., the scale scores were used assuming no measurement error; Jöreskog \& Sörbom, 1993). All other constructs were defined by the observed variables.

Measurement models for self-regulation and risk proneness were examined before testing the structural models. The results for a 12-item version of the self-regulation measure are reported elsewhere (Raffaelli et al., 2005). The present results with all 13 items are almost identical and will be summarized here. For self-regulation $(N=735)$, a one-factor model resulted in standardized factor loadings that ranged from .30 to .63; all were significant $(p<.05)$, indicating good convergent validity. The measurement model had a signifi- 


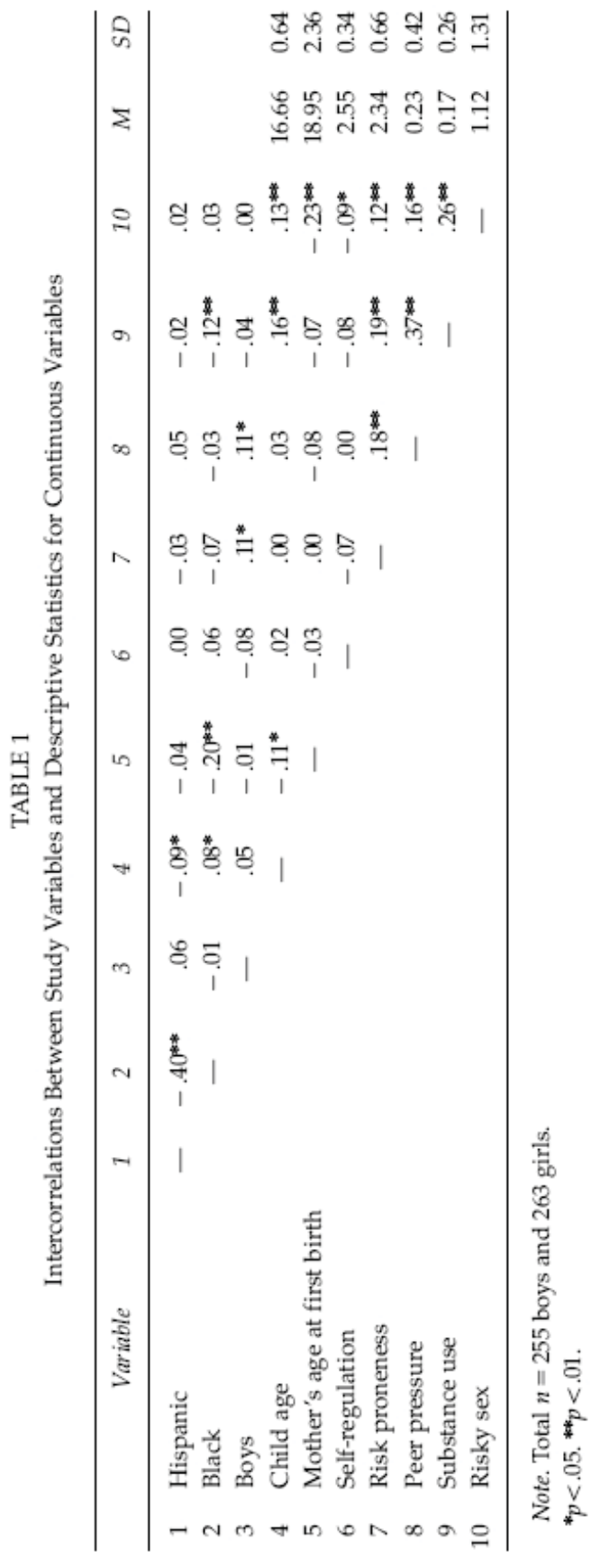

cant $\chi^{2}$, but the GFI and CFI were greater than .90 and the RMSEA was less than .10, indicating an acceptable model fit. For risk proneness $(N=618)$, the standardized factor loadings for a one-factor model were all significant $(p<$ .05 ) and ranged from .36 to .64 . The $\chi^{2}$ was significant, $\chi^{2}(9)=45.36$, but the $\mathrm{GFI}=.98, \mathrm{CFI}=.95$, and RMSEA $=.08$ indicated good fit (results available from L. Crockett).

\section{Structural Equation Models Examining Pathways to Risky Sexual Behavior}

The basic structural model was examined in the primary cohort already described and a second cohort (described below). The results of the SEM for both cohorts are shown in Figure 2, which includes the standardized solutions for each path (coefficients for the primary cohort are outside the parentheses; coefficients for the alternative cohort are inside) and the error variance of each endogenous latent variable. To simplify presentation, the individual indicators for self-regulation and risk proneness are not shown. Direct paths from child gender, race/ethnicity, age, and mother's age at first birth to sexual risk taking were also tested. As can be seen in Figure 2, significant paths were found between self-regulation and substance use and between risk proneness and both peer pressure and substance use. As expected, the path from self-regulation to substance use was negative, whereas the paths from risk proneness to substance use and peer pressure were positive; however, the path from self-regulation to negative peer pressure was not significant. In line with expectations, negative peer pressure was positively associated with substance use, and both substance use and peer pressure positively predicted sexual risk taking. The indirect effect of self-regulation on sexual risk taking through substance use was significant but small $(-.01)$. The total effect of risk proneness on sexual risk taking, including the three indirect paths (via peer pressure, substance use, and both), was significant, with a standardized coefficient of .08. None of the demographic variables predicted sexual risk scores. This model, which included no direct paths from self-regulation and risk proneness to risky sexual behavior, showed an acceptable fit, $\chi^{2}(296, N=518)=1,363.10, \mathrm{p}<.001$; $\mathrm{GFI}=.90 ; \mathrm{CFI}=.91 ; \mathrm{RMSEA}=.084$.

Because the structural model was informed in part by prior analyses using the same cohort, there was a risk that the current results were specific to this cohort and would not generalize to other samples. To examine the robustness of the results, we conducted a replication analysis using a different cohort of children from the NLSY dataset. This cohort was chosen using the same criteria as the original cohort, except that the children were born 2 years later (i.e., 


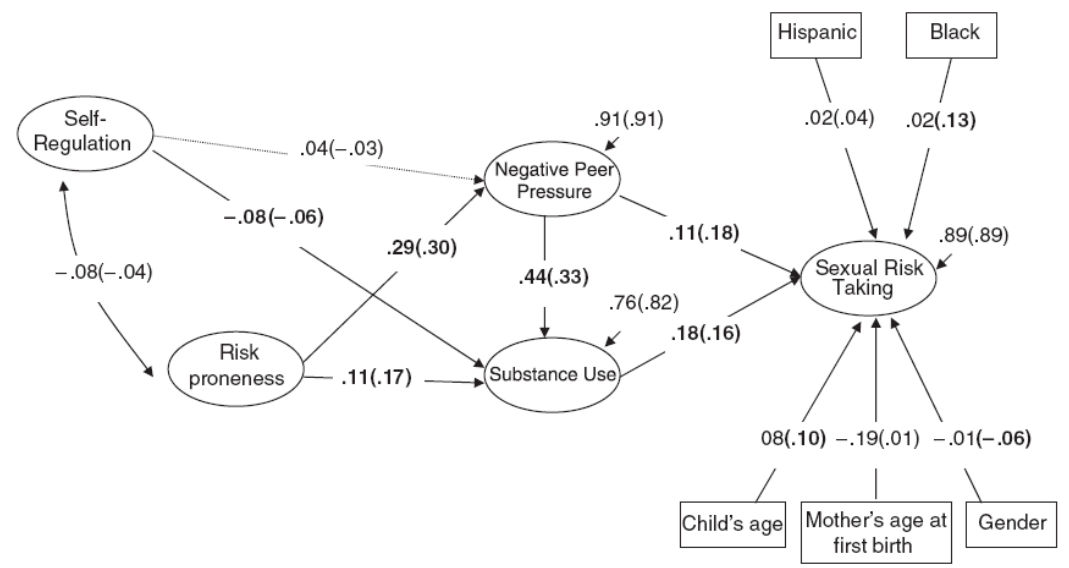

FIGURE2 Structural model showing indirect paths from self-regulation to risky sexual behavior in two cohorts (all coefficients are standardized. Numbers in bold are significant coefficients. The dotted lines indicate nonsignificant paths. Coefficients for the alternative cohort are in parentheses).

in 1983-1984 instead of 1981-1982). As in the main cohort, data from ages $8-9,12-13$, and 16-17 were included. The structural model showed an acceptable fit for the alternative cohort, $\chi^{2}(290, n=384)=1,340.01, p<.001$, $\mathrm{GFI}=.90, \mathrm{CFI}=.91, \mathrm{RMSEA}=.10$, and the same primary paths were significant as in the initial cohort (see Figure 2, coefficients in parentheses). ${ }^{1}$ Differences were found in the effects of demographic variables: child gender, age, and being of African American descent had significant effects on risky sexual behavior only in the second cohort. Apart from these minor differences, the structural model was replicated in the second cohort. Therefore, all subsequent analyses were based on the primary cohort.

To determine whether the direct effects from self-regulation and risk proneness to sexual risk were also significant, we tested a second model that included these paths using the main cohort. The second model showed an acceptable fit, $\chi^{2}(294, n=518)=1,367.56, p<.001, \mathrm{GFI}=.91, \mathrm{CFI}=.91$, and RMSEA

${ }^{1}$ Five pairs of correlated errors were added to achieve this level of fit. This was deemed ac ceptable because the correlated errors were in the measurement part of the model (between item assessing either self-regulation or risk proneness) and because structural paths were not affected.
$=.084$. The path from self-regulation to sexual risk taking was negative and significant (coefficient $=-.10$ ). Moreover, when the path from self-regulation to sexual risk taking was set to 0 , the resulting $\chi^{2}$ difference was significant $\left(\chi^{2}\right.$ difference $=7.91, p<.01)$. In contrast, the direct path from risk proneness to sexual risk taking was not significant. These results provide evidence that the impact of risk proneness on risky sexual behavior is explained by substance use and negative peer pressure, whereas the influence of self-regulation is not explained by these variables.

\section{Gender Differences}

To examine whether the model differed for boys and girls, a two-group model without any constraints was initially tested. This model showed an acceptable fit to the data, $\chi^{2}=1,688.86, p<.001, \mathrm{CFI}=.91$, RMSEA $=.09$. Next, we tested a model in which all structural paths were constrained to be equal for boys and girls. This model showed a similar fit, $\chi^{2}=1,713.48, p<$ .001 , CFI $=.91$, and RMSEA $=.09$, but a $\chi^{2}$ difference test revealed a significant difference between the two models, $\chi^{2}$ difference $=24.33, d f=7, p<$ .001 , indicating that although the overall model did not differ for boys and girls, some structural paths differed by gender.

To identify which paths differed by gender, we successively freed each path in turn and compared the fit of the resulting model with that of the model in which all structural paths were constrained to be equal for girls and boys. $\chi^{2}$ difference tests revealed three significant gender differences, corresponding to the paths from self-regulation to substance use, from peer pressure to substance use, and from substance use to sexual risk taking. The path from self-regulation to substance use was stronger for girls (unstandardized coefficient $=-.22$ for girls versus -.08 for boys); it was significant for girls only. The path coefficient from substance use to sexual risk taking was larger for girls than boys and was significant for girls (coefficient $=.24$ ) but not for boys (coefficient $=.06$ ). In contrast, the impact of peer pressure on substance use was significant for both genders but greater for boys than girls (coefficient $=.55$ versus .33 )

\section{DISCUSSION}

The overarching goal of the current study was to examine a model linking children's self-regulatory capacity and risk proneness to their involvement in 
risky sexual behavior as adolescents. The longitudinal data allowed us to examine relations between self-regulation during middle childhood (ages 8-9) and sexual risk taking during adolescence (ages 16-17), providing a rigorous test of claims that individual characteristics have implications for later sexual risk taking (e.g., Feldman \& Weinberger, 1994). We also examined two proposed mediators of this association: negative peer pressure and substance use at ages $12-13$. The same indirect pathways were examined for risk proneness, a second psychological predictor of sexual risk taking. To our knowledge, this study is among the first to examine the pathways through which early selfregulation influences sexual behavior in adolescence.

Prior research has demonstrated associations between aspects of children's self-regulation and adolescent substance use and delinquency (Aytaclar et al., 1999; Block et al., 1988; Caspi et al., 1995; Farrell \& Danish, 1993), between adolescent substance use and sexual behavior (Jessor, 1998), and between self-regulation, and risky sexual behavior (Feldman \& Brown, 1993; Raffaelli \& Crockett, 2003). Building on this research base, the present study tested an integrative model incorporating the direct and indirect pathways through which childhood self-regulation influences risky sexual behavior. The results revealed that self-regulation in middle childhood influences adolescent sexual risk taking both directly and indirectly, through early adolescent substance use. Children whose mothers rated them as high on selfregulation at ages 8-9 reported lower substance use at ages 12-13. In turn, early adolescent substance use predicted risky sexual behavior 4 years later. Thus, poor self-regulation appears to set children on a path to sexual risk taking in part by increasing early substance use. Yet, the indirect effect of self-regulation on sexual behavior was small, indicating that other processes are likely involved. Furthermore, self-regulation showed a direct relation to risky sexual behavior. Some research suggests that self-regulation shows fairly stable individual differences (Block et al., 1998; Caspi et al., 1995; Murphy et al., 1999; Raffaelli et al., 2005). Thus, children who are poor selfregulators may become adolescents with self-regulatory deficits who are vulnerable to multiple forms of risky behavior, including early substance use and sexual risk taking.

In contrast, early adolescent risk proneness appeared to operate indirectly on sexual risk taking through effects on concurrent substance use and negative peer pressure. Risk proneness predicted both negative peer pressure and early experimentation with substances; in turn, substance use predicted sexual risk taking directly, and negative peer pressure predicted sexual risk taking both directly and indirectly, through early substance use. Thus, risk proneness (a combination of attraction to excitement and a preference for spontaneity as opposed to forethought) appears to affect subse- quent risky sexual behavior by leading youth into association with peers who encourage misconduct and by increasing early experimentation with substances, which in turn increases sexual risk taking. Once these effects were considered, the direct effect of risk proneness was not significant. Research focused on sensation seeking (e.g., Farley, 1991) has tended to examine direct effects on risky behavior, based on the notion that youth who are motivated by excitement are likely to be attracted to novelty and danger (Tarter, 2002). However, the present results suggest that for sexual risk taking, risk proneness may operate indirectly through negative peer pressure and early substance use.

Based on the current findings, poor self-regulation in childhood and early adolescent risk proneness each influence risky sexual behavior in part by increasing early substance use. The role of substance use in risky sex has been recognized in previous studies. Using substances before or during a sexual encounter is thought to increase sexual risk taking by impairing decision-making skills and reducing inhibition (Finnigan \& Hammersley, 1992; Koelega, 1995; Peterson et al., 1990), and girls' general level of alcohol use is associated with unwanted sexual intercourse (Buzy et al., in press). The longitudinal relations revealed in the current study may reflect the initiation in early adolescence of a longer-term pattern of substance use that is linked to greater sexual risk taking throughout adolescence. Alternatively, the longitudinal impact of substance use on risky sexual behavior may reflect the emergence of what Jessor and colleagues refer to as a syndrome of problem behaviors (e.g., Costa, Jessor, Donovan, \& Fortenberry, 1995), such that adolescents who use substances are also prone to other problem behaviors including risky sex. Experimentation with substances tends to precede sexual debut (Grunbaum et al., 2004), so early substance use could serve as an early marker of a broader tendency toward problem behavior. In either case, substance use during early adolescence may function as an early warning sign of future involvement in risky sexual behavior.

As expected, negative peer pressure in early adolescence predicted adolescent risky sexual behavior. Previous research indicates that affiliation with peers who encourage misconduct is associated with sexual behavior both directly and indirectly, through early substance use (Brown et al., 1986; Rodgers \& Rowe, 1990; Whitbeck et al., 1993; Windle, 2000). The present findings add to this picture, suggesting that risk proneness, an individual characteristic, increases the likelihood that youth will embark on this path. Because risk proneness, peer pressure, and substance use were measured concurrently, the temporal relations among them cannot be established in the present study. Disentangling these temporal relations would be a useful avenue for future research. 
Exploratory analyses of gender differences in pathways revealed that the overall structural model did not differ for boys and girls. However, significant albeit small gender differences were observed in the strength of individual paths. First, the path from substance use to sexual risk taking was significantly stronger for girls than boys, suggesting that early substance use makes girls particularly vulnerable to risky sex. Substance use is associated with decreased vigilance (Koelega, 1995; Peterson et al., 1990) and, insofar as girls are expected to be the sexual gatekeepers (Gagnon, 1973), reduced vigilance by girls may be especially conducive to risky sex. Second, self-regulation exerted a stronger effect on substance use for girls than boys, contrary to a prior study by Farrell and Danish (1993). However, those authors focused on emotional restraint and examined short-term associations over a 6-month interval in early adolescence, whereas we used a multidimensional measure of selfregulation and examined associations over a 4-year period from childhood to early adolescence. Additional research is needed to sort out the reasons for this apparent age-related shift in the pattern of gender differences. Third, although peer pressure was positively associated with early substance use for both genders, the effect was stronger for boys than girls. Moreover, contrary to some prior research on peer influences (Smith et al., 1985), there was no gender difference in the association between negative peer pressure and sexual risk taking. The divergent results may reflect differences in peer measures. Smith et al. (1985) measured peer influence indirectly by examining the association between self-reported sexual behavior and best friend's sexual behavior; this association could reflect modeling as well as direct pressure. In contrast, we assessed negative peer pressure as perceived by the adolescent. Although intriguing, these gender patterns are based on exploratory analyses and require replication in future studies.

The present findings suggest that poor self-regulation and risk proneness may increase risky sexual behavior by influencing exposure to negative peer pressure or increasing early substance use. Based on these results, peer pressure and experimentation with substances may be useful targets for intervention in early adolescence, although substance use interventions may be more successful in reducing girls' sexual risk taking than that of boys. It is also potentially feasible to intervene in self-regulation: enhancing self-regulation could reduce both early substance use and risky sexual behavior. However, to be effective, such interventions might need to occur quite early (i.e., before ages 8-9), given that other research shows little change in the mean levels of self-regulation after middle childhood (Raffaelli et al., 2005).

Although the NLSY offers many advantages for developmental researchers, including large sample sizes and an extended longitudinal design, use of an existing dataset imposes constraints on how study constructs are operation- alized. For example, the self-regulation measure in the present study was derived from maternal report items intended to assess behavior problems. Although the validity of parent reports has been supported in other studies and the present measure included items similar to those used in prior developmental research, replication with more direct measures of self-regulation would be useful. Additionally, the sexual behavior questions were not as precise as might be hoped (e.g., condom use was reported only for most recent intercourse, and number of sexual partners was reported for the last year). Risk proneness was not assessed in middle childhood, so this construct had to be measured in early adolescence, concurrent with the proposed mediators. Ideally, both risk proneness and self-regulation would be measured in middle childhood in order to compare their impact on the intervening variables and adolescent sexual risk taking. Finally, the NLSY cohort selected for study was comprised disproportionately of the children of early childbearers. Although this might have biased the results, our ability to replicate the structural model in a cohort of children born to older mothers suggests otherwise and bolsters confidence in the generalizability of the findings.

Despite these limitations, the present study adds to the literature on adolescent sexual behavior by examining an integrative model that incorporates the pathways through which individual characteristics such as self-regulation and risk proneness operate to influence sexual risk taking. To our knowledge, this is the first study to examine the impact of self-regulation assessed in middle childhood on risky sexual behavior among both boys and girls. In addition to confirming the importance of self-regulation and risk proneness as individual-level factors associated with later risk behavior, the current findings indicated that peer pressure and substance use in early adolescence may constitute intervening processes that link these characteristics to sexual risk taking. The current findings, together with our prior analyses (Raffaelli \& Crockett, 2003), suggest that risky sexual behavior is the culmination of a developmental pathway marked by low self-regulation, risk proneness, and early involvement in substance use.

\section{ACKNOWLEDGMENTS}

This research was funded by grant \# R01-MH62977 to M. Raffaelli and L. Crockett from the National Institutes of Health. Research assistance was provided by Myesha Albert, Brett Avila, Jennifer Bowers, Rebecca Col-man, Jenenne Geske, Sam Hardy, Roya Hossaini, Kristin Moilanen, Andy Peytchev, and Devan Starks. 


\section{REFERENCES}

Aytaclar, S., Tarter, R., Kirisci, L., \& Lu, S. (1999). Association between hyperactivity and executive cognitive functioning in childhood and substance abuse in early adolescence. Journal of the American Academy of Child and Adolescent Psychiatry, 38, 172-178.

Barkley, R. A. (1997). ADHD and the nature of self-control. New York: Guilford.

Baumeister, R. F., Leith, K. P., Muraven, M., \& Bratslavsky, E. (1998). Self-regulation as a key to success in life. In D. Pushkar, W. Bukowski, A. E. Schwartzman, D. M. Stack, \& D. R. White (Eds.), Improving competence across the lifespan: Building interventions based on theory and research (pp. 117-132). New York: Plenum.

Beyth-Marom, R., \& Fischoff, B. (1997). Adolescents' decisions about risks: A cognitive perspective. In J. Schulenberg, J. L. Maggs, \& K. Hurrelmann (Eds.), Health risks and developmental transitions during adolescence (pp. 110-135). Cambridge, UK: Cambridge University Press.

Block, J. H., \& Block, J. (1980). The role of ego-control and ego-resiliency in the organization of behavior. In W. A. Collins (Ed.), Development of cognition, affect and social relations: The Minnesota Symposia on Child Psychology (Vol. 13, pp. 39-101). Hillsdale, NJ: Erlbaum.

Block, J., Block, J. H., \& Keyes, S. (1988). Longitudinally foretelling drug usage in adolescence: Early childhood personality and environmental precursors. Child Development, 59, 336-355.

Brody, G. H., \& Ge, X. (2001). Linking parenting processes and self-regulation to psychologica functioning and alcohol use during adolescence. Journal of Family Psychology, 15, 82-94

Bronson, M. B. (2000). Self-regulation in early childhood: Nature and nurture. New York: Guilford.

Brown, B. B., Clasen, D. R., \& Eicher, S. (1986). Perceptions of peer pressure, peer conformity dispositions, and self reported behavior among adolescents. Developmental Psychology, $22,521-530$.

Buzy, W. M., McDonald, R., Jouriles, E. N., Swank, P. R., Rosenfeld, D., Smikek, J. S., et al. (2004). Adolescent girls' alcohol use as a risk factor for relationship violence. Journal of Research on Adolescence, 14, 449-470.

Caspi, A., Henry, B., McGee, R. O., Moffitt, T. E., \& Silva, P. A. (1995). Temperamental origin of child and adolescent behavior problems: From age three to age fifteen. Child Development, 66, 55-68.

Colder, C. R., \& Chassin, L. (1997). Affectivity and impulsivity: Temperament risk for adolescent alcohol involvement. Psychology of Addictive Behaviors, 11, 83-97.

Cooper, M. L. (1994). Motivations for alcohol use among adolescents: Development and validation of a four-factor model. Psychological Assessment, 6, 117-128.

Costa, F. M., Jessor, R., Donovan, J. E., \& Fortenberry, J. D. (1995). Early initiation of sexual intercourse: The influence of psychosocial unconventionality. Journal of Research on Adolescence, 5, 93-121.

Demetriou, A. (2000). Organization and development of self-understanding and self-regulation In M. Zeidner (Ed.), Handbook of self-regulation (pp. 209-251). San Diego, CA: Academic Press.

Diaz, R. M., \& Fruhauf, A. G. (1991). The origins and development of self-regulation: A developmental model on the risk for addictive behaviours. In N. Heather, W. R. Miller, \& J. Greeley (Eds.), Self-control and the addictive behaviours (pp. 83-106). City, Australia: Maxwell Macmillan Publishing.

Eisenberg, N., \& Fabes, R. A. (1999). Emotion, emotion-related regulation, and quality of socioemotional functioning. In L. Balter \& C. S. Tamas-LeMonda (Eds.), Child psychology: $A$ handbook of contemporary issues (pp. 318-335). Philadelphia: Psychology Press.
Eisenberg, N., Fabes, R. A., Murphy, B., Maszk, P., Smith, M., \& Karbon, M. (1995). The role of emotionality and regulation in children's social functioning: A longitudinal study. Child Development, 66, 1360-1384.

Eysenck, S. B. G., \& Eysenck, H. J. (1978). Impulsiveness and venturesomeness: Their position in a dimensional system of personality description. Psychological Reports, 43, 1247-1255.

Farley, F. (1991). The type-t personality. In L. P. Lipsitt \& L. L. Mitnick (Eds.), Self-regulatory behavior and risk taking: Causes and consequences (pp. 371-382). Norwood, NJ: Ablex.

Farrell, A. D., \& Danish, S. (1993). Peer drug associations and emotional restraint: Causes or consequences of adolescents' drug use? Journal of Consulting and Clinical Psychology, 61, $327-334$.

Feldman, S. S., \& Brown, N. L. (1993). Family influences on adolescent male sexuality: The mediational role of self-restraint. Social Development, 2, 15-35.

Feldman, S. S., \& Weinberger, D. A. (1994). Self-restraint as a mediator of family influences on boys' delinquent behavior: A longitudinal study. Child Development, 65, 195-211.

Finnigan, F., \& Hammersley, R. (1992). The effects of alcohol on performance. In A. P. Smith, \& D. M. Jones (Eds.), Handbook of human performance (Vol. 2, pp. 73-126). London: Academic Press.

Gagnon, J. H. (1973). Scripts and the coordination of sexual conduct. Nebraska Symposium on Motivation, 21, 27-59.

Grunbaum, J. A., Kann, L., Kinchen, S., Ross, J., Hawkins, J., \& Lowry, R., et al. (2004). Youth risk behavior surveillance-United States, 2003. In Surveillance Summaries, May 21, 2004 Morbidity and Mortality Weekly Report, 53 (No. SS-2).

Guerin, D. W., \& Gottfried, A. W. (1994). Developmental stability and change in parent reports of temperament: A ten-year longitudinal investigation from infancy through preadolescence. Merrill-Palmer Quarterly, 40, 334-355.

Jessor, R. (1998). New perspectives on adolescent risk behavior. In R. Jessor (Ed.), New perspec tives on adolescent risk behavior (pp. 1-10). New York: Cambridge University Press.

Jöreskog, K., \& Sörbom, D. (1993). LISREL ${ }^{\circledR}$ 8: Structural equation modeling with the SIMPLISTM command language. Lincolnwood, IL: Scientific Software International.

Jöreskog, K., \& Sörbom, D. (2002). LISREL (Version 8.5) [Computer software]. Scientific Software International Inc. Lincolnwood, IL.

Kelloway, E. K. (1998). Using LISREL for structural equation modeling. Thousand Oaks, CA: Sage.

Kline, R. B. (1998). Principles and practice of structural equation modeling. New York: Guilford Press.

Koelega, H. S. (1995). Alcohol and vigilance performance. A review. Psychopharmacology, 118 , 233-249.

Kopp, C. B. (1982). Antecedents of self-regulation: A developmental perspective. Developmental Psychology, 18, 199-214.

Lengua, L. (2002). The contribution of emotionality and self-regulation to the understanding of children's response to multiple risk. Child Development, 73, 144-161.

Little Known Variables in the NLS: Risk Tolerance (2000). NLS News, 00-100, 6-7.

Miller, B. C., Benson, B., \& Galbraith, K. A. (2001). Family relationships and adolescent pregnancy risk: A research synthesis. Developmental Review, 21, 1-38.

Moore, K., Manlove, J., Terry-Humen, E., Williams, S., Papillo, A. R., \& Scarpa, J. (2001). Child trends: Facts at a glance 2001. Retrieved on December 16, 2002, from Child Trends Web site: http://www.childtrends.org

Murphy, B., Eisenberg, N., Fabes, R. A., Shepard, S., \& Guthrie, I. K. (1999). Consistency and 
change in children's emotionality and regulation: A longitudinal study. Merrill-Palmer Quarterly, 45, 413-444.

Pederson, W., \& Skrondal, A. (1996). Alcohol and sexual victimization: A longitudinal study of Norwegian girls. Addictions, 91, 565-581.

Peterson, J. B., Rothfleisch, J., Zelazo, P. D., \& Pihl, R. O. (1990). Acute alcohol intoxication and cognitive functioning. Journal of Studies on Alcohol, 51, 114-122.

Peterson, J. L., \& Zill, N. (1986). Marital disruption, parent-child relationships, and behavioral problems in children. Journal of Marriage and the Family, 48, 295-307.

Raffaelli, M., \& Crockett, L. C. (2003). Sexual risk taking in adolescence: The role of self-regulation and attraction to risk. Developmental Psychology, 39, 1036-1046.

Raffaelli, M., Crockett, L. J., \& Shen, Y. (2005). Developmental stability and change in self-regulation from childhood to adolescence. Journal of Genetic Psychology, 166, 54-75.

Rawlings, D., Boldero, J., \& Wiseman, F. (1995). The interaction of age with impulsiveness and venturesomeness in the prediction of adolescent sexual behavior. Individual Differences, 19, $117-120$.

Rodgers, J. L., \& Rowe, D. C. (1990). Adolescent sexual activity and mildly deviant behavior. Journal of Family Issues, 11, 274-293.

Rothbart, M. K., \& Bates, J. E. (1998). Temperament. In N. Eisenberg (Volume Ed.) W. Damon (Series Ed.), Handbook of child psychology, Vol. 3: Social, emotional, and personality development (pp. 105-176). New York: Wiley.

Shonkoff, J. P., \& Phillips, D. A. (2000). From neurons to neighborhoods: The science of early childhood development. Washington, DC: National Academy Press.

Smith, E. A., Udry, J. R., \& Morris, N. M. (1985). Pubertal development and friends: A biosocial explanation of adolescent sexual behavior. Journal of Health and Social Behavior, 26, 183192.

Tarter, R. E. (2002). Etiology of adolescent substance abuse: A developmental perspective. The American Journal on Addictions, 11, 171-191.

Tarter, R. E., Kirisci, L., Mezzich, A., Cornelius, J. R., Pajer, K., \& Vanyukov, M., et al. (2003). Neurobehavioral disinhibition in childhood predicts early age of at onset of substance use disorder. American Journal of Psychiatry, 160, 1078-1085.

Whitbeck, L., Conger, R., \& Kao, M. (1993). The influence of parental support, depressed affect, and peers on the sexual behaviors of adolescent girls. Journal of Family Issues, 14, 261-278.

Windle, M. (2000). Parental, sibling, and peer influences on adolescent substance use and alcohol problems. Applied Developmental Science, 4, 98-110.

Zagorsky, J. L., \& White, L. (1999). NLSY79 user's guide: A guide to the 1979-1998 National longitudinal survey of youth data. Washington, DC: U.S. Department of Labor.

Zill, N. (1990). Behavioral problems index based on parent report. (Publication No. 9103). Washington, DC: Child Trends.

Zimmerman, B. J. (2000). Attaining self-regulation: A social cognitive perspective. In M. Boekaerts, P. R. Pintrich, \& M. Zeidner (Eds.), Handbook of self-regulation (pp. 13-39). San Diego, CA: Academic.

Zucker, R. A., Fitzgerald, H. E., \& Moses, H. D. (1995). Emergence of alcohol problems and the several alcoholisms: A developmental perspective on etiologic theory and life course trajectory. In D. Cicchetti, \& D. J. Cohen (Eds.), Developmental psychopathology. Vol. 2: Risk, disorder, and adaptation (pp. 677-711). New York: John Wiley \& Sons.

Zuckerman, M. (1991). Sensation seeking: The balance between risk and reward. In L. P. Lipsitt, \& L. L. Mitnick (Eds.), Self-regulatory behavior and risk taking: Causes and consequences (pp. 143-152). Norwood, NJ: Ablex.

\section{APPENDIX}

TABLE A1

Study Measures and Time of Assessment

\begin{tabular}{lcll}
\hline \multicolumn{3}{c}{ Time of Assessment } \\
\hline 1986 & 1990 & \multicolumn{1}{c}{1994} & 1998 \\
\hline $\begin{array}{l}\text { Gender } \\
\text { Race }\end{array}$ & Self-regulation & $\begin{array}{l}\text { Risk proneness } \\
\text { Substance use }\end{array}$ & $\begin{array}{l}\text { Age } \\
\text { Mother's age at first } \\
\quad \text { child's birth }\end{array}$ \\
$\begin{array}{l}\text { Mother's education } \\
\text { Family structure }\end{array}$ & Negative peer pressure & \\
\hline
\end{tabular}

